\title{
Interactions between apolar, basic and acidic model oils and a calcite surface
}

\author{
Liu, Xiaoyan; Feilberg, Karen Louise; Yan, Wei; Stenby, Erling Halfdan; Thormann, Esben
}

Published in:

Journal of Dispersion Science and Technology

Link to article, DOI:

$10.1080 / 01932691.2018 .1523012$

Publication date:

2019

Document Version

Peer reviewed version

Link back to DTU Orbit

Citation (APA):

Liu, X., Feilberg, K. L., Yan, W., Stenby, E. H., \& Thormann, E. (2019). Interactions between apolar, basic and acidic model oils and a calcite surface. Journal of Dispersion Science and Technology, 40(11), 1611-1617. https://doi.org/10.1080/01932691.2018.1523012

\section{General rights}

Copyright and moral rights for the publications made accessible in the public portal are retained by the authors and/or other copyright owners and it is a condition of accessing publications that users recognise and abide by the legal requirements associated with these rights.

- Users may download and print one copy of any publication from the public portal for the purpose of private study or research.

- You may not further distribute the material or use it for any profit-making activity or commercial gain

- You may freely distribute the URL identifying the publication in the public portal 


\title{
Interactions between Apolar, Basic and Acidic Model Oils and a Calcite Surface
}

\author{
Xiaoyan Liu ${ }^{1,2,3}$, Karen L. Feilberg ${ }^{2}$, Wei Yan ${ }^{1}$, Erling H. Stenby ${ }^{1}$, Esben Thormann ${ }^{1 *}$ \\ ${ }^{1}$ Department of Chemistry, Technical University of Denmark, Kemitorvet 206, 2800 Kongens \\ Lyngby, Denmark \\ ${ }^{2}$ Centre for Olie og Gas - Technical University of Denmark, Elektrovej 375, 2800 Kongens Lyngby, \\ Denmark \\ ${ }^{3}$ Key Laboratory of Applied Surface and Colloid Chemistry of Ministry of Education, School of \\ Chemistry and Chemical Engineering, Shaanxi Normal University, Xi'an 710062, China. \\ * Corresponding author: Department of Chemistry, Technical University of Denmark, Kemitorvet \\ 206, 2800, Kgs. Lyngby, Denmark, tel: +45 452524 39, email: esth@kemi.dtu.dk
}

\begin{abstract}
In this study, the atomic force microscopy colloidal probe technique was employed to investigate the interaction between apolar, basic and acidic model oil probes and a calcite surface in solutions containing different concentrations of $\mathrm{NaCl}, \mathrm{CaCl}_{2}$ and $\mathrm{Na}_{2} \mathrm{SO}_{4}$. In the presence of $\mathrm{SO}_{4}{ }^{2-}$, hydration and structural forces were observed between apolar model oil probes and a calcite surface on approach. Relatively low adhesion forces were observed between the basic model oil probes and the calcite surface, while higher adhesion forces were observed between the acidic model oil probes and the calcite surface. Furthermore, the adhesion forces between the basic model oil probes and the calcite surface significantly increased in the presence of $\mathrm{SO}_{4}{ }^{2-}$, while the adhesion force between the acidic model oil probes and the calcite surface decreased in the presence of $\mathrm{Ca}^{2+}$ or $\mathrm{SO}_{4}{ }^{2-}$. The differences in the adhesion forces are related to electrostatic attraction and ion bridging forces between the model oil probes and the calcite surface.
\end{abstract}

KEYWORDS: model oil, surface forces, ions effects, calcite surface

\section{Introduction}

Wettability alteration has been proposed to be one of the primary parameters for improving oil recovery in both sandstone and carbonate reservoirs. ${ }^{(1-3)}$ By injecting aqueous salt solutions to an oil reservoir, a water film can be formed between the oil and the mineral surfaces. The thickness of the water film determines the wettability of the reservoir surfaces; i.e., for a very thick water film, the surface of the reservoir is said to be water-wet, which improves oil recovery due to a reduced adsorption between polar components and mineral surfaces. ${ }^{(4)}$ Low-salinity water-flooding with 
salinity lower than $5000 \mathrm{ppm}$ has been found to be able to improve oil recovery ${ }^{(5)}$ due to wettability alteration of reservoir surfaces. ${ }^{(6-8)}$ The mechanisms of low-salinity water-flooding leading to wettability alteration are not yet fully understood, but various parameters, such as specific ion adsorption, ${ }^{(9-11)} \mathrm{pH}$, electrostatic double layer expansion, multi-ion exchange, ${ }^{(12)}$ and chemical mechanisms, ${ }^{(3,13-14)}$ are important.

Manipulation of the surface forces between oil layers and reservoir surfaces has been proposed as a possibly important mechanism for wettability alteration in the reservoir. The forces include van der Waals forces, electrical double layer forces, hydrophobic interactions, hydration forces, bridging forces and structural forces. ${ }^{(15)}$ Very recently, direct force measurements between calcite surfaces, ${ }^{(16)}$ between oil layers and calcite surfaces, ${ }^{(17-18)}$ and between oil layers and mica surfaces ${ }^{(19)}$ were executed by atomic force microscopy (AFM). All these studies were performed using either a nanometer-scaled sharp AFM-tip or a piece of calcite without a well-defined geometry. To obtain a calcite probe with a well-defined geometry in the force measurement, Sauerer et al. used the focused ion beam (FIB) technique to fabricate a calcite particle for investigating the interactions between calcite particle and calcite surface in an organic solvent. ${ }^{(20)}$ The AFM colloidal probe technique $^{(21-23)}$ has also been employed to study the interactions between a calcite surface and a silica colloidal probe. ${ }^{(15)}$ However, to date, only a few studies have addressed surface forces in systems including calcite surfaces.

Our previous study on oil release from $\mathrm{CaCO}_{3}$ surfaces indicates that apolar, basic, and acidic oil components in crude oil have different contributions to the oil adsorption and desorption processes. ${ }^{(3)}$ Moreover, Li et al. investigated interaction between silica nanoparticle and calcite surface $^{(24)}$, and between carbon nanoparticle and calcite surface ${ }^{(25)}$ indicating the interactions between the nanoparticles and calcite surface influenced by ionic strength and species of ions. In this study, we have fabricated three model oil probes to simulate apolar, basic and acidic oil components, i.e., different functional groups represented in heavy oil components, and the AFM colloidal probe technique is then used to investigate the surface forces between these model oil probes and a calcite surface in aqueous salt solutions of $\mathrm{NaCl}, \mathrm{CaCl}_{2}$ and $\mathrm{Na}_{2} \mathrm{SO}_{4}$. This approach allows us to study how salinity and potential determining ions affect the attractive and repulsive forces between calcite and different model oil components.

\section{Materials and Methods}


Solutions and sample preparation. Aqueous electrolyte solutions were prepared by dissolving sodium chloride ( $\mathrm{NaCl}, 99.5 \%$, Sigma-Aldrich), calcium chloride $\left(\mathrm{CaCl}_{2}, 96 \%\right.$, anhydrous, SigmaAldrich), and sodium sulfate $\left(\mathrm{Na}_{2} \mathrm{SO}_{4}, 99.0 \%\right.$, anhydrous, Sigma-Aldrich) in Milli-Q water (resistivity $=18.2 \mathrm{M} \Omega \mathrm{cm}$, organic content $\leq 5 \mathrm{ppb}$, at $25^{\circ} \mathrm{C}$ ) purified by employing a Milli-ROPls unit connected to a Milli-Q plus 185 system and filtered through a $0.2 \mu \mathrm{m}$ Millipak filter. A low salinity $(60 \mathrm{mM}) \mathrm{NaCl}$ containing solution and high salinity $(600 \mathrm{mM}) \mathrm{NaCl}, \mathrm{CaCl}_{2} / \mathrm{NaCl}$ and $\mathrm{Na}_{2} \mathrm{SO}_{4} / \mathrm{NaCl}$ containing solutions were prepared. For the $600 \mathrm{mM} \mathrm{CaCl} / 2 \mathrm{NaCl}$ and $600 \mathrm{mM}$ $\mathrm{Na}_{2} \mathrm{SO}_{4} / \mathrm{NaCl}$ high salinity solutions, the specific concentrations of $\mathrm{Ca}^{2+}(10 \mathrm{mM})$ and $\mathrm{SO}_{4}{ }^{2-}(28$ $\mathrm{mM}$ ) were chosen to mimic the concentrations of the ions in sea water, ${ }^{(26)}$ and $\mathrm{NaCl}$ was used to keep a constant ionic strength of $600 \mathrm{mM}$. The $\mathrm{pH}$ values of the solutions were measured with an 827-pH lab (Metrohm, Switzerland); however, the values did not vary significantly among the different solutions. The salinity, composition and $\mathrm{pH}$ of the four different solutions are reported in Table 1.

Table 1 . Salinity and composition of the aqueous salt solutions

\begin{tabular}{|l|l|l|l|l|}
\hline & $\mathrm{NaCl}$ & $\mathrm{NaCl}$ & $\mathrm{CaCl}_{2} / \mathrm{NaCl}$ & $\mathrm{Na}_{2} \mathrm{SO}_{4} / \mathrm{NaCl}$ \\
\hline Concentration $(\mathrm{mM})$ & 60 & 600 & $10 / 570$ & $28 / 516$ \\
\hline Ionic strength $(\mathrm{mM})$ & 60 & 600 & 600 & 600 \\
\hline $\mathrm{pH}$ & $5.67 \pm 0.03$ & $5.62 \pm 0.02$ & $5.72 \pm 0.02$ & $5.60 \pm 0.04$ \\
\hline
\end{tabular}

Thermally oxidized silicon wafers with a $100 \mathrm{~nm}$ thick $\mathrm{SiO}_{2}$ layer were purchased from WaferNet, Inc., USA. Silica particles with a diameter of approximately $20 \mu \mathrm{m}$ were purchased from Kisker Biotech, Germany. Rectangular cantilevers, CSC38/tipless/Cr-Au, purchased from MikroMasch, Germany, with the approximate dimensions of $250 \mu \mathrm{m}$ in length and $32.5 \mu \mathrm{m}$ in width, were used for the AFM force measurements. The spring constants of the cantilevers were determined by the Sader method. ${ }^{(27-28)}$ After calibration, a silica particle was glued to the end of the cantilever with the assistance of an Eppendorf Micromanipulator (PatchMan NP 2), a Nikon Eclipse LV100ND microscope and a small amount of epoxy glue (Araldite, Rapid). The exact size of the particles was determined by using the microscope, employing image analysis with Infinity Analyzer (Lumenera Corporation). The prepared cantilevers with silica particles were cleaned using a plasma cleaner (Harrick PDC-3XG, New York) for 40 seconds. After plasma cleaning, the cantilevers with silica 
particles and the silica surfaces were modified by trimethoxy(octyl)silane (96\%), (3aminopropyl)trimethoxysilane (APTES, 99\%), and (3-mercaptopropyl)trimethoxysilane (95\%), purchased from Sigma-Aldrich, Denmark, by vapor phase silanization. ${ }^{(29-32)}$ The silane based monolayers on the AFM probes and on flat silica substrates (for contact angle measurements) were prepared using a similar procedure as described in detail in our previous work. ${ }^{(29)}$ Hereafter, we will refer to the modified probes as apolar, basic and acidic model oil probes, respectively. The prepared model oil probes were used for AFM force measurements immediately after preparation. A calcite crystal (Iceland spar, Ward's science, Brazil) was cleaved from a cleaned, optical sample. The calcite crystal was rinsed with Milli-Q water, followed by blow-drying with compressed air. The sample was used for the AFM force measurements immediately after cleaning.

Contact angle measurements. The water contact angles of flat model oil surfaces and the calcite surface were determined by the sessile drop method at room temperature using an Attension Theta Lite tensiometer (Biolin Scientific, Finland). The contact angles were determined by fitting the Young-Laplace equation to the profile of a water droplet (with a volume of $1 \mu \mathrm{L}$ ) placed on the surfaces by a Hamilton syringe. The reported contact angles are the mean values of the left and right contact angles obtained at static conditions. The images of water contact angles on the surfaces are reported in Figure 1. The water contact angle of apolar model oil modified surface is $86.9 \pm 0.5^{\circ}$, which indicates the silica surface becomes hydrophobic after apolar model oil attachment compared to the bare silica surface (water contact angle is $26 \pm 1$ with the same cleaning treatment as in this work $)^{(29)}$. The water contact angles of basic model oil and acidic model oil modified surfaces are $58.6 \pm 2$ and $53.5 \pm 1^{\circ}$, respectively, which are similar although they have an opposite surface charge. The water contact angles of basic model oil and acidic model oil modified surfaces indicate that the modified silica surfaces become less hydrophilic comparing to the bare silica surface. The water contact angle of calcite surface is $52.6 \pm 0.5^{\circ}$. 


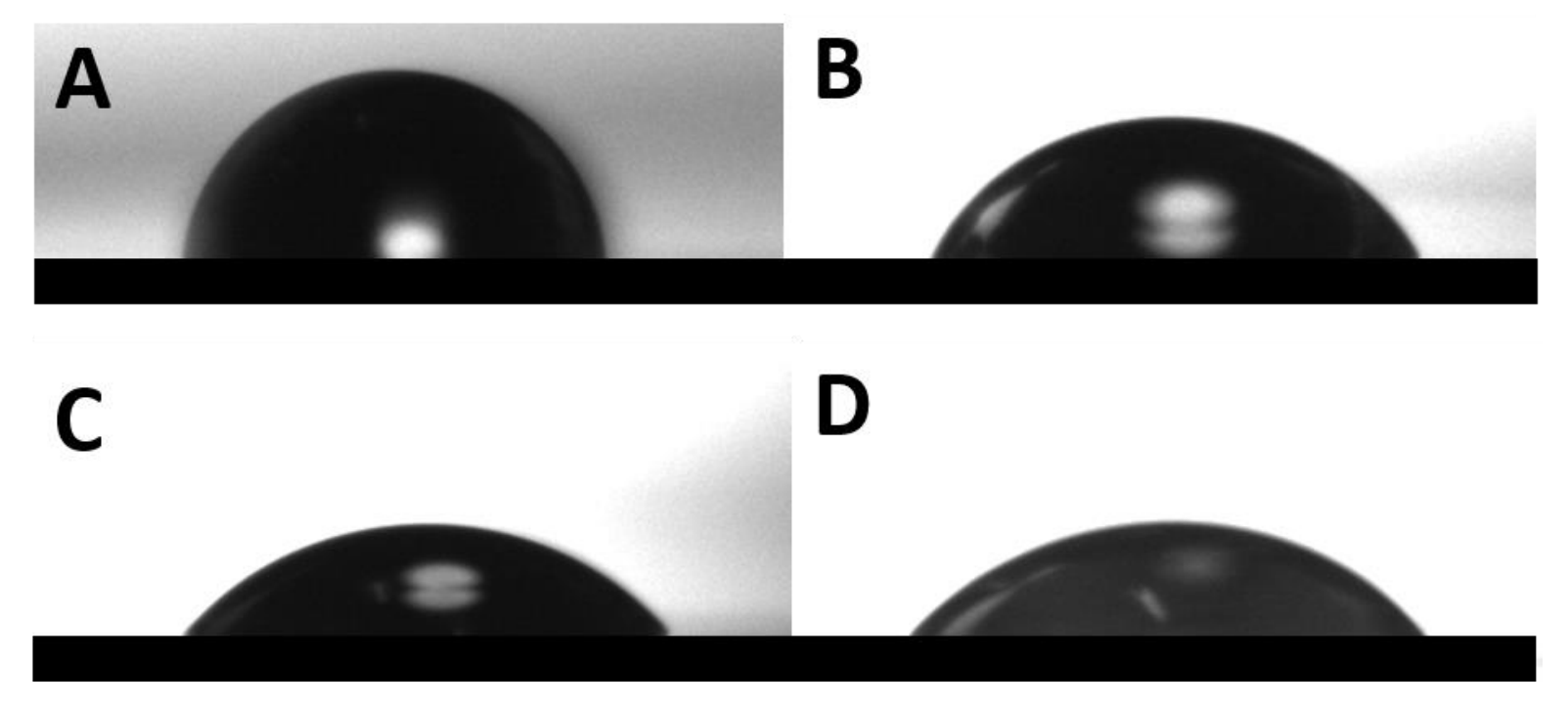

Figure 1. Images of water contact angles on apolar model oil modified silica surface (A), basic model oil modified silica surface (B), acidic model oil modified silica surface (C), and calcite surface (D).

Atomic force microscopy imaging and force measurement. The force versus separation between model oil probes and the calcite surface were measured using a NanoWizard 3 AFM (JPK Instrument, Germany). Before each experiment, the cantilever holder, O-rings and all other tools were cleaned by immersion in $2 \%$ Hellmanex (Hellma $\mathrm{GmbH}$, Germany) solution for approximately 1 hour, followed by rinsing several times with plenty of Milli-Q water and then blow-drying with compressed air. The surface forces between the different surface pairs, apolar model oil-calcite, basic model oil-calcite and acidic model oil-calcite, were measured in the aqueous salt solutions and 200 force curves were recorded at a regular spacing over a $2 \times 2 \mu \mathrm{m}^{2}$ area for each condition. All surface force measurements were executed at a constant approach and separation speed of $0.5 \mu \mathrm{m} / \mathrm{s}$, and the reported forces were normalized by the probe radius, F/R, according to the Derjaguin approximation. Tapping mode images of the calcite surface were obtained with air using a rectangular silicon cantilever (NSC15/Al BS, Mikromasch, Germany) and a scan rate of $0.3 \mathrm{~Hz}$ per line. To characterize the silica probe, it was first glued on a tipless cantilever; and then 'reverse imaged' by contact mode using a PA01 grating (Mikromasch, Germany) and a scan rate of $1 \mathrm{~Hz}$ per line. The JPK SPM data processing software was employed to analyze the recorded images. 


\section{Results and Discussion}

Before describing the results of the interactions between the model oil probes and the calcite surface, we will briefly summarize some relevant data (see Table 2) for the model oil probes determined from the AFM colloidal probe technique measurements as reported in our previous study ${ }^{(29)}$ where surface forces between different pairs of model oil layers were measured in $1 \mathrm{mM} \mathrm{NaCl}$. Based on these measurements, the surface potentials and surface charge densities of the model oil probes were determined by comparing the DLVO calculation and the measured results.

It is well-known that the exact magnitudes of the surface potential of the probes are influenced by the ionic strength and $\mathrm{pH}$ of the solutions, and while the $\mathrm{pH}$ values of the silane solutions used in this study are close to the $\mathrm{pH}$ of $1 \mathrm{mM} \mathrm{NaCl}$ (5.69), the ionic strength is significantly higher. To this end, we expect the numerical values of the surface potentials at high ionic strength to be lower than the values reported in Table 2. An exact determination of the surface potentials at high ionic strength is however difficult due to the effective screening of electrostatic double layer forces. However, in this study, we only need the qualitative information that the apolar model oil and the acidic model oil probes are negatively charged while the basic model oil probe is positively charge.

Table 2. Surface potential and surface charge density of model oil probes in $1 \mathrm{mM} \mathrm{NaCl}{ }^{(29)}$

\begin{tabular}{|l|l|l|l|}
\hline & Apolar model oil surface & Basic model oil surface & Acidic model oil surface \\
\hline$\psi(\mathrm{mV})$ & -8 & +8 & -11 \\
\hline$\sigma\left(\mathrm{C} / \mathrm{m}^{2}\right)$ & $5.8 \times 10^{-4}$ & $5.8 \times 10^{-4}$ & $8.0 \times 10^{-4}$ \\
\hline
\end{tabular}

AFM imaging. AFM topographical images of the calcite surface and the reversed image of the silica colloidal probe are shown in Figure 2. The surface roughness $(R q)$ is $0.8 \mathrm{~nm}$ for the calcite surface and $1.3 \mathrm{~nm}$ for the silica colloidal probe. These surface roughness values might reflect the roughness conditions in natural rock samples and will also have a measurable effect on the appearance of the surface forces measured by the colloidal probe technique. ${ }^{(33)}$ In this case, the effective van der Waals forces will be suppressed because of the hard-wall repulsion between the surface asperities of the silica particle and calcite surface will dominate over the attractive interactions at short separations. Moreover, in the salt solutions with ionic strengths of 60 and 600 $\mathrm{mM}$, the corresponding Debye lengths are only 1.2 and $0.4 \mathrm{~nm}$ calculated from ionic strength of the 
solutions, ${ }^{(34)}$ respectively, and the electrical double-layer force will therefore also be strongly influenced by the surface roughness. For this reason, the discussion regarding DLVO forces in this study will only be qualitative.
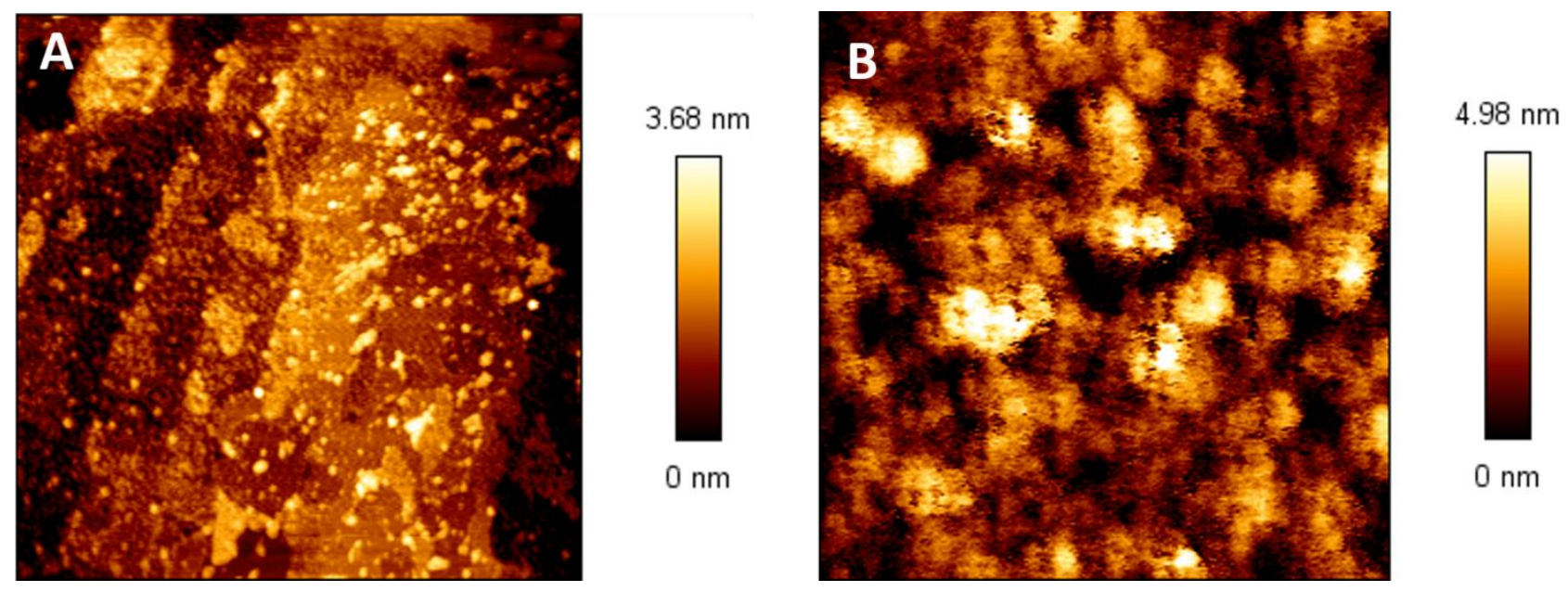

$0 \mathrm{~nm}$

Figure 2. AFM topographical images of the calcite surface (A) and silica particle (B). The image size is $1.5 \times 1.5 \mu \mathrm{m}^{2}$ for the calcite surface and $10 \times 10 \mu \mathrm{m}^{2}$ for silica particle.

Surface forces measured during approach. Figure 3 shows the representative approach force curves for the surface pairs of apolar model oil-calcite, basic model oil-calcite and acidic model oilcalcite in $60 \mathrm{mM} \mathrm{NaCl}, 600 \mathrm{mM} \mathrm{NaCl}, 600 \mathrm{mM} \mathrm{CaCl} / \mathrm{NaCl}$ and $600 \mathrm{mM} \mathrm{Na} 2 \mathrm{SO}_{4} / \mathrm{NaCl}$ solutions. The minimum forces of the surface pair in the four solutions are reported in Table 3. Figure 3A, the forces measured between the apolar model oil and calcite surface on approach are attractive in 60 $\mathrm{mM} \mathrm{NaCl}$ and $600 \mathrm{mM} \mathrm{NaCl}$. The apolar model oil at $\mathrm{pH}$ approximately 5.6 is negatively charged due to the dissociation of unreacted silanol groups on the silica surface. We will here refer to these charges localized near the silica surface as the inner charged layer, compared to the charges on the outer functional groups (i.e., $-\mathrm{SH}$ and $\left.-\mathrm{NH}_{2}\right) .{ }^{(35)}$ The calcite surface in aqueous solution has both negative charges and positive charges on it, and the net surface charge depends on various factors, such as $\mathrm{pH}$ and ionic composition in the solution. The forces between the bare silica probe and calcite are attractive in $60 \mathrm{mM} \mathrm{NaCl}$ and $600 \mathrm{mM} \mathrm{NaCl}$ solutions (See Figure $\mathrm{S} 1$ in the supporting information). This outcome indicates that the net charge of the calcite surface is positive in the $\mathrm{NaCl}$ solution. Calcite dissolves in aqueous solution (the solubility is $0.014 \mathrm{~g} / \mathrm{L}$ in water at $25{ }^{\circ} \mathrm{C}$ ), and therefore, $\mathrm{Ca}^{2+}$ ions exist in all investigated cases including the $\mathrm{NaCl}, \mathrm{CaCl}_{2} / \mathrm{NaCl}$ and $\mathrm{Na}_{2} \mathrm{SO}_{4} / \mathrm{NaCl}$ systems. These divalent cations are thus able to form ion bridges between negatively 
charged functional groups on the two approaching surfaces. We thus suggest that the attractive forces between the apolar model oil probe and calcite surface are the sum of the electrostatic attraction between the opposite charges on the surfaces, van der Waals forces and bridging forces formed between negative charges by calcium ions in $\mathrm{NaCl}$. With respect to the force measured in the $600 \mathrm{mM} \mathrm{CaCl}_{2} / \mathrm{NaCl}$ solution, it is well-known that $\mathrm{Ca}^{2+}$ is able to adsorb on negatively charged groups leading to partial neutralization of the negative surface charge or even to a reversal of the sign of the effective surface charge. ${ }^{(29)}$ Moreover, $\mathrm{Ca}^{2+}$ is a potential determining ion for calcite, meaning that it can adsorb specifically onto the weakly positively charged calcite surface in water. ${ }^{(36)}$ However, our investigation shows that the force in the $600 \mathrm{mM} \mathrm{CaCl} / \mathrm{NaCl}$ solution is attractive and similar in magnitude to the attraction measured in the $600 \mathrm{mM} \mathrm{NaCl}$ solution. This finding indicates that the increased amount of calcium ions in the system does not have any significant influence on the forces between the apolar model oil layer and calcite surface. In the presence of $\mathrm{SO}_{4}{ }^{2-}$, a long-range repulsion, starting at a surface separation of approximately $8 \mathrm{~nm}$, is observed. To this end, Pourchet et al. have found indications that $\mathrm{SO}_{4}{ }^{2-}$ can adsorb on the positively charged sites on calcite. ${ }^{(36)}$ As the silica probe approaches the calcite surface, an extra energy will thus be required to remove the highly hydrated $\mathrm{SO}_{4}{ }^{2-}$ ions from the calcite surface, which could generate hydration and structural forces in the system. We thus suggest that the long-range repulsion is due to a combination of hydration and structural forces caused by the adsorption of $\mathrm{SO}_{4}{ }^{2-}$ onto the calcite surface.


Figure 3. Force normalized by radius, F/R, as a function of separation in surface pairs of apolar model oil-calcite (A), basic model oil-calcite (B), and acidic model oil-calcite (C) in the salt solutions.

Table 3. the minimum forces, $\mathrm{F}_{\mathrm{m}} / \mathrm{R}$, of the surface pair in $60 \mathrm{mM} \mathrm{NaCl}, 600 \mathrm{mM} \mathrm{NaCl}, 600 \mathrm{mM}$ $\mathrm{CaCl}_{2} / \mathrm{NaCl}$ and $600 \mathrm{mM} \mathrm{Na} 2 \mathrm{SO}_{4} / \mathrm{NaCl}$ solutions. 


\begin{tabular}{|c|c|c|c|}
\hline & $\begin{array}{l}\mathrm{F}_{\mathrm{m}} / \mathrm{R}(\text { apolar model oil }- \\
\text { calcite) }(\mathrm{mN} / \mathrm{m})\end{array}$ & $\begin{array}{l}\mathrm{F}_{\mathrm{m}} / \mathrm{R}(\text { basic model oil- } \\
\text { calcite) }(\mathrm{mN} / \mathrm{m})\end{array}$ & $\begin{array}{l}\mathrm{F}_{\mathrm{m}} / \mathrm{R}(\text { acidic model oil- } \\
\text { calcite })(\mathrm{mN} / \mathrm{m})\end{array}$ \\
\hline $60 \mathrm{mM} \mathrm{NaCl}$ & $-0.007 \pm 0.001$ & 0 & $-0.011 \pm 0.002$ \\
\hline $600 \mathrm{mM} \mathrm{NaCl}$ & $-0.010 \pm 0.002$ & 0 & $-0.010 \pm 0.002$ \\
\hline $600 \mathrm{mM} \mathrm{CaCl}_{2} / \mathrm{NaCl}$ & $-0.007 \pm 0.001$ & 0 & $-0.002 \pm 0.0003$ \\
\hline $600 \mathrm{mM} \mathrm{Na}_{2} \mathrm{SO}_{4} / \mathrm{NaCl}$ & 0 & 0 & $-0.01 \pm 0.001$ \\
\hline
\end{tabular}

Figure 3B shows the approach forces between the basic model oil probe and calcite in the salt solutions. Here, the forces in the $60 \mathrm{mM} \mathrm{NaCl}, 600 \mathrm{mM} \mathrm{NaCl}$, and $600 \mathrm{mM} \mathrm{CaCl} / 2 \mathrm{NaCl}$ solutions are observed to be repulsive, and the greatest long-range repulsion is observed in $60 \mathrm{mM} \mathrm{NaCl}$ where the Debye length is longer compared to that in the solutions of higher ionic strength. Since both the basic model oil probe and the calcite surface are positively charged, these observations indicate that the repulsions are dominated by electrostatic repulsion. In the presence of $\mathrm{Ca}^{2+}$, the forces appear to be slightly less repulsive than that in $600 \mathrm{mM} \mathrm{NaCl}$. In the presence of $\mathrm{SO}_{4}{ }^{2-}$, we still expect specific adsorption of $\mathrm{SO}_{4}{ }^{2-}$ ions to the calcite surface, but the repulsion is much more short-range compared to the apolar model oil-calcite system. However, in this case, the adsorption of $\mathrm{SO}_{4}{ }^{2-}$ ions will lead to a decreased electrostatic repulsion, and we suggest that it is the combinations of these opposite contributions to the total force which give rise to a relatively shortrange repulsion.

The approach forces between the acidic model oil and calcite are shown in Figure 3C. The results show that the forces are attractive in the four salt solutions. We attribute these attractions in the 60 $\mathrm{mM} \mathrm{NaCl}$ and $600 \mathrm{mM} \mathrm{NaCl}$ solutions to the electrostatic attraction between the negatively charged acidic model oil probe and positively charged calcite surface. In the $600 \mathrm{mM} \mathrm{CaCl} / \mathrm{NaCl}$ solution, a less attractive force is observed. We suggest that it is because of $\mathrm{Ca}^{2+}$ neutralizing the negative charges on the acidic model oil, thus reducing the electrostatic attraction between the acidic model oil probe and the calcite surface. In the presence of $\mathrm{SO}_{4}{ }^{2-}$, the adhesion forces are expected to be decreased by hydration and structural forces due to specific adsorption of $\mathrm{SO}_{4}{ }^{2-}$ ions to the calcite surface. However, the adhesion forces are similar in magnitude in $600 \mathrm{mM} \mathrm{NaCl}$ and $600 \mathrm{mM}$ $\mathrm{Na}_{2} \mathrm{SO}_{4} / \mathrm{NaCl}$ solution. To this end, our previous study indicates that the negative charges on the acidic model oil probe are located at the outer layer of the surface. We suggest that the electrostatic attraction between these negative charges on the outer layer and the positive charges on the calcite 
surface neutralizes the repulsive hydration and structural forces due to the specific adsorption of $\mathrm{SO}_{4}{ }^{2-}$ ions to the calcite surface. Therefore, a decreased adhesion force is not observed in the presence of $\mathrm{SO}_{4}{ }^{2-}$.

Contact adhesion measured during retraction. The mean values of adhesion and the representative force curves on the separation between the three surface pairs in the salt solutions are reported in Figure 4. Figure 4A shows that the mean values of adhesion between the apolar model oil and calcite in $60 \mathrm{mM} \mathrm{NaCl}, 600 \mathrm{mM} \mathrm{NaCl}$ and $600 \mathrm{mM} \mathrm{CaCl}_{2} / \mathrm{NaCl}$ solutions are similar in magnitude. The adhesion forces between the apolar model oil and calcite are the sum of van der Waals forces, electrostatic attraction, ion bridging forces and nonspecific bonding influenced by various factors such as charge screening effect, solubility of the apolar oil and species of ions. The adhesion is similar in the $\mathrm{NaCl}$ and $\mathrm{CaCl}_{2} / \mathrm{NaCl}$ solutions even though the selected concentration and ions can vary the electrostatic attraction and ion bridging forces in the system, which indicates that van der Waals forces and nonspecific bonding dominate the adhesion in $\mathrm{NaCl}$ and $\mathrm{CaCl}_{2} / \mathrm{NaCl}$ solutions. In the presence of $\mathrm{SO}_{4}{ }^{2-}$, a decreased adhesion force is observed on the separation. Fathi et al. indicated that $\mathrm{SO}_{4}{ }^{2-}$ can adsorb on the positively charged sites on the calcite surface. ${ }^{(37)}$ This neutralizes the positive charges on the calcite surface. We attribute the decreased adhesion force to a decreased electrostatic attraction between the negatively charged apolar model oil layer and the less positively charged calcite surface caused by adsorption of $\mathrm{SO}_{4}{ }^{2-}$. 

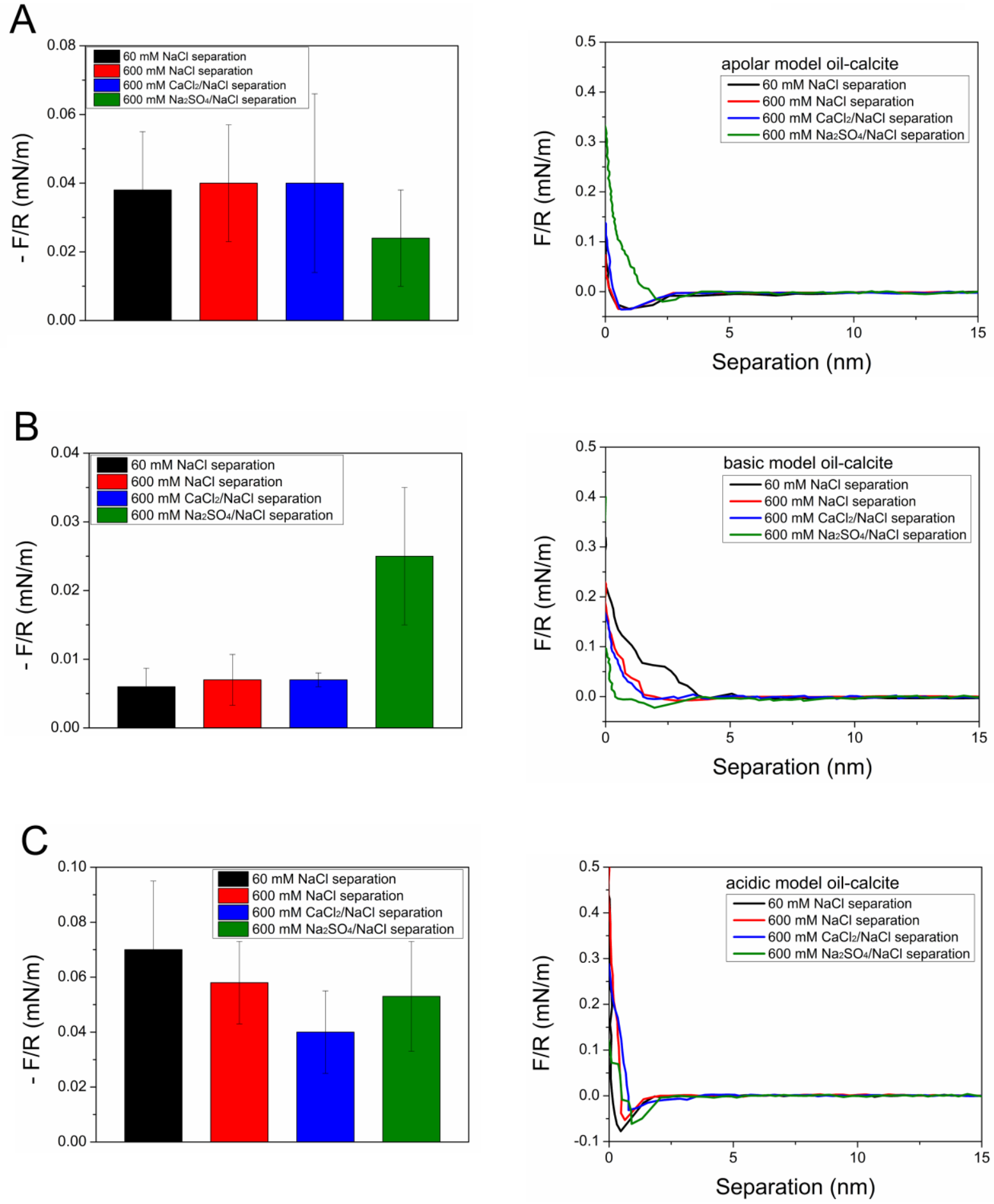

Figure 4. Mean values of adhesion forces (left panel) and representative force curves on separation (right panel) in the systems of apolar model oil-calcite (A), basic model oil-calcite (B), and acidic model oil-calcite $(\mathrm{C})$ in salt solutions.

In the basic model oil and calcite system, the adhesion force is possibly the sum of the electrostatic repulsion between positive charges on both the basic model oil layer and calcite surface and 
nonspecific binding between the basic model oil layer and calcite. The electrostatic repulsion forces lead to the relatively low adhesion compared to the other two systems (See Figure 4B). Similar to that in the apolar model oil-calcite system, the adhesion forces between the basic model oil and calcite in $60 \mathrm{mM} \mathrm{NaCl}, 600 \mathrm{mM} \mathrm{NaCl}$ and $600 \mathrm{mM} \mathrm{CaCl}_{2} / \mathrm{NaCl}$ solutions are similar in magnitude. There is no significant influence on adhesion as the salinity or the amount of calcium ions is increased. Meanwhile, the adhesion force significantly increases in the presence of $\mathrm{SO}_{4}{ }^{2-}$, and a long-range attractive force (approximately $8 \mathrm{~nm}$ ) is observed in this system. We suggest that this attraction is caused by an ion-bridging force formed by $\mathrm{SO}_{4}{ }^{2-}$ between the two positively charged basic model oil and calcite surfaces.

The information of adhesion forces in the acidic model oil-calcite system is reported in Figure 4C. As we know, the acidic model oil surface is negatively charged, and the calcite surface is positively charged in $\mathrm{NaCl}$. Therefore, the adhesion force is influenced by electrostatic attraction between negatively charged acidic model oil and positively charged calcite surface, and nonspecific binding between the acidic model oil layer and calcite surface. The results show that the adhesion force between the acidic model oil component and calcite surface in $600 \mathrm{mM} \mathrm{NaCl}$ is lower than that in $60 \mathrm{mM} \mathrm{NaCl}$. We suggest that the decreased adhesion is due to the charge screening effect. In $\mathrm{CaCl}_{2} / \mathrm{NaCl}$, the adhesion force between the acidic oil layer and calcite surface is lower than in 600 $\mathrm{mM} \mathrm{NaCl} . \mathrm{Ca}^{2+}$ is able to adsorb on the negatively charged acidic model oil surface, which leads to a decreased electrostatic attraction between the acidic model oil and calcite leading to a decreased adhesion. In the presence of $\mathrm{SO}_{4}{ }^{2-}$, the adhesion force between the acidic model oil probe and calcite slightly decreases comparing to that in $600 \mathrm{mM} \mathrm{NaCl}$. We attribute this to a decreased electrostatic attraction between the surfaces due to the less positively charged calcite surface caused by $\mathrm{SO}_{4}{ }^{2-}$ adsorbing on the positive charges on the calcite surface.

\section{Conclusions}

We have measured the surface forces in the systems of apolar model oil-calcite, basic model oilcalcite and acidic model oil-calcite to investigate the effects of salinity, calcium, and sulfate ions on binding to and release of different functional groups from calcite. From the surface force measurements, we conclude that the calcite is positively charged in the $\mathrm{NaCl}$ solutions. Moreover, strong and long-range hydration and structural forces are generated between the apolar model oil probe and calcite surface as $\mathrm{SO}_{4}{ }^{2-}$ into the systems. 
In the apolar model oil-calcite and basic model oil-calcite systems, the adhesion forces are similar in magnitude in $60 \mathrm{mM}$ and $600 \mathrm{mM} \mathrm{NaCl}$ solutions. Meanwhile, in the system of acidic model oilcalcite, a decreased adhesion force is observed with increasing ionic strength of $\mathrm{NaCl}$, which is attributable to a charge screening effect.

For apolar model oil-calcite and basic model oil-calcite in $\mathrm{CaCl}_{2}$, the adhesion is comparable to the adhesion observed in $600 \mathrm{mM} \mathrm{NaCl}$, while the adhesion decreases in the system of acidic model oil surface-calcite in $\mathrm{CaCl}_{2}$, compared to that in $600 \mathrm{mM} \mathrm{NaCl}$. In the latter case, this occurs because adsorption of $\mathrm{Ca}^{2+}$ on the negatively charged acidic probe reduces the electrostatic attraction between the negatively charged acidic probe and the positively charged calcite surface.

When $\mathrm{SO}_{4}{ }^{2-}$ is present, the adhesion force decreases in the systems of apolar model oil-calcite and acidic model oil-calcite. We attribute the decreased adhesion force to the decreased electrostatic attraction due to the adsorption of $\mathrm{SO}_{4}{ }^{2-}$ on the calcite surface. Meanwhile, the adhesion force significantly increases in the system of basic model oil-calcite surface, compared to that in $600 \mathrm{mM}$ $\mathrm{NaCl}$. We suggest that this is attributable to an ion-bridging formed by $\mathrm{SO}_{4}{ }^{2-}$ between the positively charged basic model oil and the positively charged calcite surface.

\section{Acknowledgments}

The research leading to these results has received funding from the Danish Hydrocarbon Research and Technology Centre (Centre for Oil and Gas - DTU) under the Advanced Water Flooding program.

\section{References}

1. Ding, H.; Rahman, S. Experimental and theoretical study of wettability alteration during low salinity water flooding-an state of the art review. Colloids and Surfaces A: Physicochemical and Engineering Aspects 2017, 520, 622-639.

2. Myint, P.C.; Firoozabadi, A. Thin liquid films in improved oil recovery from low-salinity brine. Current Opinion in Colloid \& Interface Science 2015, 20, 105-114.

3. Liu, X.; Yan, W.; Stenby, E.H.; Thormann, E. Release of Crude Oil from Silica and Calcium Carbonate Surfaces: On the Alternation of Surface and Molecular Forces by High- and Low-Salinity Aqueous Salt Solutions. Energy Fuels 2016, 30, 3986-3993.

4. Hirasaki, G.J. Wettability: Fundamentals and Surface Forces.

5. Jadhunandan, P.P.; Morrow, N.R. Effect of Wettability on Waterflood Recovery for CrudeOil/Brine/Rock Systems. 1995.

6. Sheng, J.J. Critical review of low-salinity waterflooding. Journal of Petroleum Science and Engineering 2014, 120, 216-224.

7. Berg, S.; Cense, A.W.; Jansen, E.; Bakker, K. Direct Experimental Evidence of Wettability Modification By Low Salinity. 2010. 
8. Aslan, S.; Fathi Najafabadi, N.; Firoozabadi, A. Non-monotonicity of the Contact Angle from $\mathrm{NaCl}$ and $\mathrm{MgCl} 2$ Concentrations in Two Petroleum Fluids on Atomistically Smooth Surfaces. Energy \& Fuels 2016, 30, 2858-2864.

9. Mugele, F.; Bera, B.; Cavalli, A.; Siretanu, I.; Maestro, A.; Duits, M.; Cohen-Stuart, M.; van den Ende, D.; Stocker, I.; Collins, I. Ion adsorption-induced wetting transition in oil-water-mineral systems. Scientific Reports 2015, 5, 10519.

10. Jiménez-Ángeles, F.; Firoozabadi, A. Contact Angle, Liquid Film, and Liquid-Liquid and LiquidSolid Interfaces in Model Oil-Brine-Substrate Systems. The Journal of Physical Chemistry C 2016, 120, 11910-11917.

11. Karimi, M.; Al-Maamari, R.S.; Ayatollahi, S.; Mehranbod, N. Impact of Sulfate lons on Wettability Alteration of Oil-Wet Calcite in the Absence and Presence of Cationic Surfactant. Energy \& Fuels 2016, 30, 819-829.

12. RezaeiDoust, A.; Puntervold, T.; Strand, S.; Austad, T. Smart Water as Wettability Modifier in Carbonate and Sandstone: A Discussion of Similarities/Differences in the Chemical Mechanisms. Energy \& Fuels 2009, 23, 4479-4485.

13. Austad, T.; Rezaeidoust, A.; Puntervold, T. Chemical Mechanism of Low Salinity Water Flooding in Sandstone Reservoirs. Society of Petroleum Engineers, 2010.

14. Yousef, A.A.; Al-Saleh, S.H.; Al-Kaabi, A.; Al-Jawfi, M.S. Laboratory Investigation of the Impact of Injection-Water Salinity and Ionic Content on Oil Recovery From Carbonate Reservoirs. 2011.

15. Diao, Y.; Espinosa-Marzal, R.M. Molecular insight into the nanoconfined calcite-solution interface. Proceedings of the National Academy of Sciences of the United States of America 2016, 113, 12047-12052.

16. Røyne, A.; Dalby, K.N.; Hassenkam, T. Repulsive hydration forces between calcite surfaces and their effect on the brittle strength of calcite-bearing rocks. Geophys. Res. Lett. 2015, 42, 4786-4794.

$17 . \quad H a s s e n k a m$, T.; Skovbjerg, L.L.; Stipp, S.L.S. Probing the intrinsically oil-wet surfaces of pores in North Sea chalk at subpore resolution. Proceedings of the National Academy of Sciences 2009, 106, 6071-6076.

18. Generosi, J.; Ceccato, M.; Andersson, M.P.; Hassenkam, T.; Dobberschütz, S.; Bovet, N.; Stipp, S.L.S. Calcite Wettability in the Presence of Dissolved Mg2+ and SO42-. Energy \& Fuels 2017, 31, 1005-1014. 19. Wu, J.; Liu, F.; Chen, G.; Wu, X.; Ma, D.; Liu, Q.; Xu, S.; Huang, S.; Chen, T.; Zhang, W.; Yang, H.; Wang, J. Effect of lonic Strength on the Interfacial Forces between Oil/Brine/Rock Interfaces: A Chemical Force Microscopy Study. Energy \& Fuels 2016, 30, 273-280.

20. Sauerer, B.; Stukan, M.; Abdallah, W.; Derkani, M.H.; Fedorov, M.; Buiting, J.; Zhang, Z.J. Quantifying mineral surface energy by scanning force microscopy. Journal of Colloid and Interface Science 2016, 472, 237-246.

21. Ducker, W.A.; Senden, T.J.; Pashley, R.M. Direct measurement of colloidal forces using an atomic force microscope. Nature 1991, 353, 239-241.

22. Butt, H.-J.; Cappella, B.; Kappl, M. Force measurements with the atomic force microscope: Technique, interpretation and applications. Surf. Sci. Rep. 2005, 59, 1-152.

23. Liu, X.; Dedinaite, A.; Rutland, M.; Thormann, E.; Visnevskij, C.; Makuska, R.; Claesson, P.M. Electrostatically Anchored Branched Brush Layers. Langmuir 2012, 28, 15537-15547.

$24 . \quad \mathrm{Li}$, Y.V.; Cathles, L.M. Retention of silica nanoparticles on calcium carbonate sands immersed in electrolyte solutions. Journal of Colloid and Interface Science 2014, 436, 1-8.

25. Li, Y.V.; Cathles, L.M. The surface interactions of a near-neutral carbon nanoparticle tracer with calcite. Journal of Nanoparticle Research 2016, 18, 71.

26. Dickson, A.G.; Special Research Grant Program 89-7A, G.S.o.C.D.i.t.O. Handbook of Methods for the Analysis of the Various Parameters of the Carbon Dioxide System in Sea Water: Prepared for the U.S. Department of Energy, Special Research Grant Program 89-7A: Global Survey of Carbon Dioxide in the Oceans, 1994. 
27.

Green, C.P.; Lioe, H.; Cleveland, J.P.; Proksch, R.; Mulvaney, P.; Sader, J.E. Normal and torsional spring constants of atomic force microscope cantilevers. Review of Scientific Instruments 2004, 75, 1988-1996.

28. Sader, J.E.; Chon, J.W.M.; Mulvaney, P. Calibration of rectangular atomic force microscope cantilevers. Review of Scientific Instruments 1999, 70, 3967-3969.

29. Liu, X.; Feilberg, K.L.; Yan, W.; Stenby, E.H.; Thormann, E. Electrical Double-Layer and lon Bridging Forces between Symmetric and Asymmetric Charged Surfaces in the Presence of Mono- and Divalent lons. Langmuir 2017, 33, 4426-4434.

30. Wasserman, S.R.; Tao, Y.T.; Whitesides, G.M. Structure and reactivity of alkylsiloxane monolayers formed by reaction of alkyltrichlorosilanes on silicon substrates. Langmuir 1989, 5, 1074-1087. 31. Haensch, C.; Hoeppener, S.; Schubert, U.S. Chemical modification of self-assembled silane based monolayers by surface reactions. Chem. Soc. Rev. 2010, 39, 2323-2334.

32. Wang, Y.; Lieberman, M. Growth of Ultrasmooth Octadecyltrichlorosilane Self-Assembled Monolayers on SiO2. Langmuir 2003, 19, 1159-1167.

33. Thormann, E. Surface forces between rough and topographically structured interfaces. Current Opinion in Colloid \& Interface Science 2017, 27, 18-24.

34. Israelachvili, J. Intermolecular and Surface Forces. 1992.

35. Liu, X.; Dedinaite, A.; Nylander, T.; Dabkowska, A.P.; Skoda, M.; Makuska, R.; Claesson, P.M. Association of anionic surfactant and physisorbed branched brush layers probed by neutron and optical reflectometry. Journal of Colloid and Interface Science 2015, 440, 245-252.

36. Pourchet, S.; Pochard, I.; Brunel, F.; Perrey, D. Chemistry of the calcite/water interface: Influence of sulfate ions and consequences in terms of cohesion forces. Cem. Concr. Res. 2013, 52, 22-30. 37. Fathi, S.J.; Austad, T.; Strand, S. Water-Based Enhanced Oil Recovery (EOR) by "Smart Water": Optimal Ionic Composition for EOR in Carbonates. Energy \& Fuels 2011, 25, 5173-5179. 